Ferroelectrics, 1996, Vol. 183, pp. 181-183 Reprints available directly from the publisher Photocopying permitted by license only
- 1996 OPA (Overseas Publishers Association) Amsterdam B.V. Published in The Netherlands under license by Gordon and Breach Sclence

Publishers SA

Printed in Malaysia

\title{
THE NONLINEAR OPTICAL PROPERTIES OF $\mathrm{Sn}_{2} \mathrm{P}_{2} \mathrm{~S}_{6}$
}

\author{
A. ANEMA ${ }^{1}$, A. GRABAR ${ }^{2}$ and Th. RASING ${ }^{1}$ \\ 1 Research Instute for Materials, University Nijmegen, Toernooiveld 1, NL- \\ 6525 ED Nijmegen, The Netherlands \\ ${ }^{2}$ Dep. Physics and Chemistry of Solid State, Uzhgorod State University, Pid- \\ hirna 46, 294000, Uzhgorod, Ukraine
}

(Received July 4, 1995)

Abstract We have studied the optical second harmonic generation (SHG) from a Sn${ }_{2} \mathrm{P}_{2} \mathrm{~S}_{6}$ crystal for fundamental wavelengths between 1100 to $1200 \mathrm{~nm}$. The SHG signal was compared with that from a KTP crystal and it was found that $\mathrm{d}_{21}\left(\mathrm{Sn}_{2} \mathrm{P}_{2} \mathrm{~S}_{6}\right)=3.6^{*} \mathrm{~d}_{33}(\mathrm{KTP})$.

\section{INTRODUCTION .}

$\mathrm{Sn}_{2} \mathrm{P}_{2} \mathrm{~S}_{6}$ is a monoclinic nonlinear optical crystal and at room temperature it has a transmission range from 550 to $8000 \mathrm{~nm}$. These two qualities make $\mathrm{Sn}_{2} \mathrm{P}_{2} \mathrm{~S}_{6}$ a very interesting material for nonlinear optical processes in the infrared.

To determine the nonlinear optical coefficients of $\mathrm{Sn}_{2} \mathrm{P}_{2} \mathrm{~S}_{6}$, the optical second harmonic generation (SHG) has been studied as a function of the incident wavelength, and compared with the SHG signal from KTP.

\section{EXPERIMENTAL SET-UP}

For the wavelength dependent SHG experiments an optical parametric oscillator (OPO) with a KTP crystal was used. This OPO was angle tuned and pumped with the second harmonic of a Nd:YAG laser, producing 7 ns pulses in the wavelength region from 950 to $1210 \mathrm{rm}$.

The two generated beams of the OPO were separated with a polarizer and the lowest frequency of these two was used for the experiment. This beam was focused by a 10 cm lens into the sample and the SHG signal was detected with a photomultiplier in combination with a monochromator.

\section{MEASUREMENTS AND RESULTS}

The $\mathrm{Sn}_{2} \mathrm{P}_{2} \mathrm{~S}_{6}$ crystal, grown by the Bridgemann method at the Uhzgorod State University, was cut parallel to the xy-plane and had a thickness of $2.25 \mathrm{~mm}$. The flux grown KTP reference crystal, was cut parallel to the $\mathrm{xz}$-plane and had a thickness of $3.45 \mathrm{~mm}$.

For the measurements on KTP the fundamental beam was polarized along the $\mathrm{z}$ direction. This gives an SHG signal, which is polarized along the z-direction, due to 


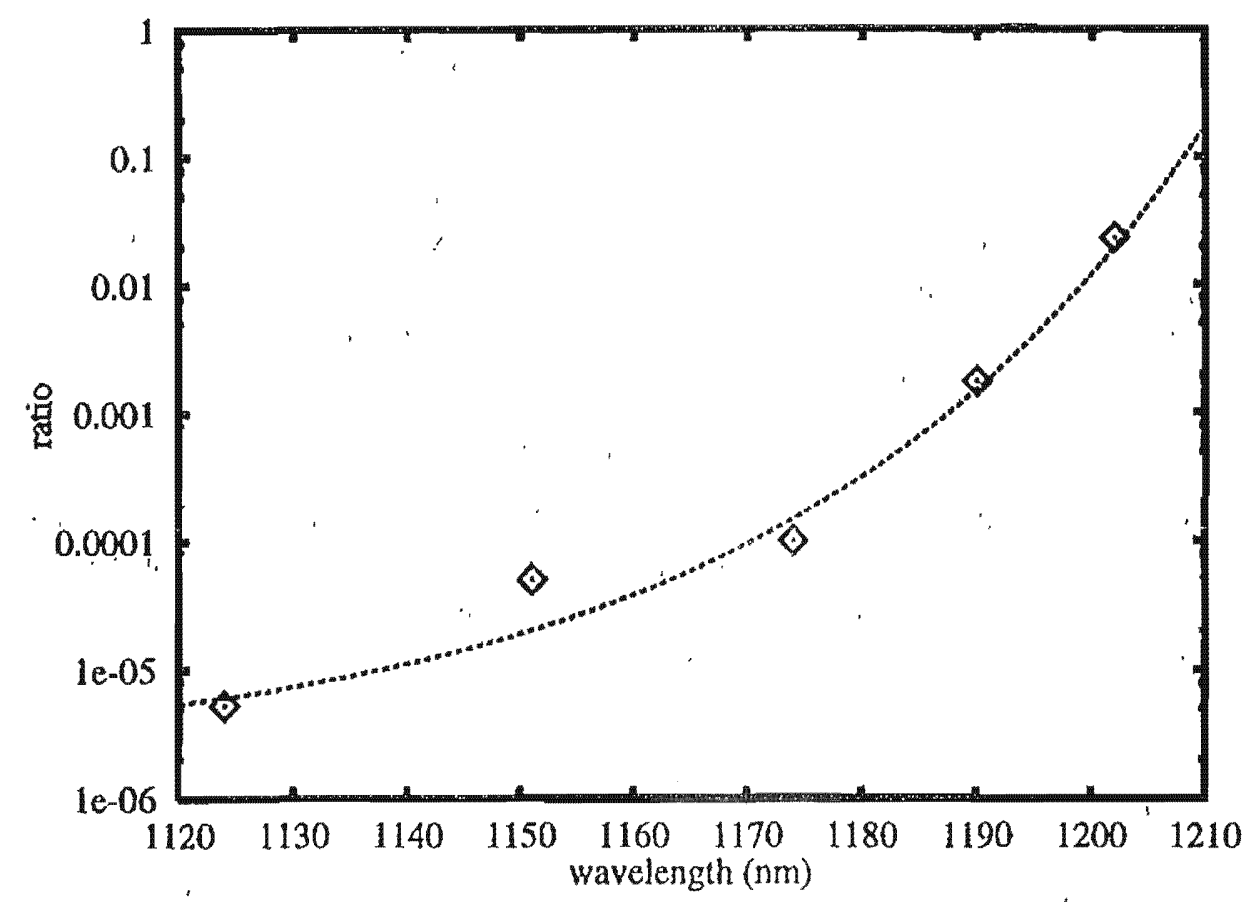

FIGURE 1: SHG signal from $\mathrm{Sn}_{2} \mathrm{P}_{2} \mathrm{~S}_{6}$ divided by the $\mathrm{SHG}$ signal from KTP as a function of the fundamental wavelength. The dashed line is a guide to the eye.

the nonlinear optical coefficient $d_{33}$. To measure the Maker-fringes the crystal was rotated in the $x y$-plane. In this way there are no other $d$-coefficients involved in the SHG process.

For the measurements on $\mathrm{Sn}_{2} \mathrm{P}_{2} \mathrm{~S}_{6}$ the fundamental beam was polarized in the $\mathrm{xz}$ plane and the detected SHG signal was polarized along the $y$-direction. The rotation for the Maker fringes was made in the xz-plane. In this case the SHG signal will depend on $d_{21}, d_{23}$ and $d_{25}$, because $S_{2} P_{2} S_{6}$ is a monoclinic crystal ${ }^{1}$. Due to the fact that $\mathrm{Sn}_{2} P_{2} \mathrm{~S}_{6}$ has a high refractive index (table 1) the influence from $d_{23}$ and $\mathrm{d}_{25}$ at a small angle of incidence can be neglected.

In figure 1 the ratio between the SHG signal from $\mathrm{Sn}_{2} \mathrm{P}_{2} \mathrm{~S}_{6}$ and KTP is plotted as a function of the fundamental wavelength, showing a strong increase of this ratio for higher wavelengths. This increase can be ascribed to the fact that for $\mathrm{Sn}_{2} \mathrm{P}_{2} \mathrm{~S}_{6}$ the SHG wavelength lies near its absorption edge of $550 \mathrm{~nm}$.

To calculate the nonlinear optical coefficients of $\mathrm{Sn}_{2} \mathrm{P}_{2} \mathrm{~S}_{6}$ we have assumed that at $600 \mathrm{~nm}$, the absorption might be neglected. In that case the conversion efficiency $\eta$ at a Maker-fringe maximum is given by':

$$
\eta=\frac{P_{2 \omega}}{P_{\omega}}=\frac{2 d_{e f f}^{2}}{\varepsilon_{0} \cdot c n_{\omega}^{2} n_{2 \omega}} \frac{P_{\omega}}{A} \frac{1}{\left(n_{2 \omega}-n_{\omega}\right)^{2}}
$$


where $\mathrm{P}_{\omega}$ is the power of the fundamental input beam, $\mathrm{P}_{2 \omega}$ is the power of the generated SHG beam, $\lambda$ is the fundamental wavelength, $n_{\omega}$ is the refractive index at $\omega$ and $A$ is the spotsize. $\mathrm{d}_{\text {eff }}$ is the effective nonlinear coefficient and depends on the propagation direction and polarization of the fundamental beam.

In the case of KTP $d_{e f f}$ is equal to $d_{33}$ and for $\mathrm{Sn}_{2} \mathrm{P}_{2} \mathrm{~S}_{6}$ it is equal to $\mathrm{d}_{21}$.

Calculating $\mathrm{d}_{21}\left(\mathrm{Sn}_{2} \mathrm{P}_{2} \mathrm{~S}_{6}\right)$ with the help 'of eq. (1), correcting for the Fresnel losses and using the refractive indices as given in table 1 , we find for a fundamental wavelength of $1200 \mathrm{~nm}$

$$
d_{21}\left(S n_{2} P_{2} S_{6}\right)=3.6 d_{33}(K T P)
$$

Vanherzeele et al. $^{2}$ measured $\mathrm{d}_{33}(\mathrm{KTP})=18.5 \mathrm{pm} / \mathrm{V}$ at a fundamental wavelength of $880 \mathrm{~nm}$. Making use of Miller's rule gives $\mathrm{d}_{33}(\mathrm{KTP})=16.2 \mathrm{pm} / \mathrm{V}$ at $1200 \mathrm{~nm}$ and thus it follows that $\mathrm{d}_{21}\left(\mathrm{Sn}_{2} \mathrm{P}_{2} \mathrm{~S}_{6}\right)=58 \mathrm{pm} / \mathrm{V}$ at this wavelength.

TABLE I. Refractive indices for $\mathrm{KTP}^{3}$ and $\mathrm{Sn}_{2} \mathrm{P}_{2} \mathrm{~S}_{6}$ at 600 and $1200 \mathrm{~nm}$

\begin{tabular}{rrrrr} 
& \multicolumn{2}{c}{ KTP } & \multicolumn{2}{c}{$\mathrm{Sn}_{2} \mathrm{P}_{2} \mathrm{~S}_{6}$} \\
& $600 \mathrm{~nm}$ & $1200 \mathrm{~nm}$ & $600 \mathrm{~nm}$ & $1200 \mathrm{~nm}$ \\
\hline $\mathrm{n}_{1}$ & $1.7 \overline{67}$ & 1.734 & 3.161 & 2.846 \\
$\mathrm{n}_{2}$ & 1.776 & 1.742 & 3.070 & 2.814 \\
$\mathrm{n}_{3}$ & 1.872 & 1.825 & 2.980 & 2.739 \\
\hline
\end{tabular}

\section{CONCLUSIONS}

The nonlinear coefficient $d_{21}$ of $\mathrm{Sn}_{2} \mathrm{P}_{2} \mathrm{~S}_{6}$ is very high compared to KTP, even if we assume that at $600 \mathrm{~nm}$ there is no absorption.

So we can conclude that $\mathrm{Sn}_{2} \mathrm{P}_{2} \mathrm{~S}_{6}$ is a very promising material for nonlinear optical processes in the infrared, because of its high nonlinear coefficient and its transparancy up to $8000 \mathrm{~nm}$.

\section{ACKNOWLEDGEMENTS}

Part of this work was supported by the Innovatieve Onderzoeks Projecten (IOP), which are financially supported by the Ministry of Economic Affairs. A. Grabar acknowledges financial support by the RIM.

\section{REFERENCES}

1. V.G. Dmitriev, G.G. Gurzadyan, D.N. Nokogosyan, Handbook of nonlinear optical crystals (Springer-Verlag, Berlin, 1991), p.42

2. H. Vanherzeele and J.D. Bierlein, Opt. Lett. 17, 982, 1992

3. T.Y. Fan, C.E. Huang, B.Q. Hu, R.C. Eckardt, Y.X. Fan, R.L. Byer and R.S. Feigelson, Appl. Opt. 26, 2390, 1987 